\title{
Plasma Species and Coating Compositions in Aluminum Treated by PEO Using Shot Square Pulse
}

\author{
Richelly N. de Lima ${ }^{a}$, Jussier de O. Vitoriano ${ }^{b}$, Marcos Ferreira Jra ${ }^{a}$, Clodomiro Alves Junior ${ }^{a, b *}$ (iD \\ ${ }^{a}$ Universidade Federal do Semiárido, Programa de Pós-Graduação em Ciências e Engenharia de \\ Materiais, 59625-900, Mossoró, RN, Brasil \\ ${ }^{b}$ Universidade Federal do Rio Grande do Norte, Programa de Pós-Graduação em Engenharia \\ Mecânica, 59078-970, Natal, RN, Brasil
}

Received: July 27, 2019; Revised: April 21, 2020; Accepted: May 5, 2020

\begin{abstract}
Up to now, plasma electrolytic oxidation (PEO) has been either produced direct current or ultra-low frequency $(<1 \mathrm{kHz})$ pulsed discharge using high concentration alkaline-silicate electrolytic $\left(\mathrm{Na}_{2} \mathrm{SiO}_{3}>8 \mathrm{~g} . \mathrm{L}^{-1}\right.$ with presence of $\left.\mathrm{KOH}\right)$. In order to contribute to these studies, the effect of current pulse width and time duration was investigated using diluted silicate electrolytic $\left(\mathrm{Na}_{2} \mathrm{SiO}_{3} 2\right.$ g.L $\left.\mathrm{L}^{-1}\right)$ and high pulse frequencies $(>1 \mathrm{kHz}$ ). The PEO process was performed on pure aluminum to try to explain how the phases composing the coatings are formed and distributed over the treatment time. For this, was made in situ monitoring using optical emission spectroscopy (OES) coupled with CCD camera. The crystalline phases evolution in the sample surface was investigated using grazing incidence X-ray diffraction (GIXRD). Regarding the evolution of ceramic phases, it is possible to verify that, internally, the predominant phase is rhombohedral $\alpha-\mathrm{Al}_{2} \mathrm{O}_{3}$ but, superficially, the predominant phase is cubic $\gamma-\mathrm{Al}_{2} \mathrm{O}_{3}$. It was verified the presence of $\mathrm{Si}$ on the borders of the pores or in proximity to cracks, especially in the treatments with higher pulse width. SEM analysis shows a reduction of the superficial porosity and an increase in coating thickness with pulse width and treatment time.
\end{abstract}

Keywords: $\mathrm{PEO}$, pulsed plasma, aluminum, coatings, $\mathrm{Al}_{2} \mathrm{O}_{3}$.

\section{Introduction}

Plasma electrolytic oxidation (PEO) is an electrochemical plasma-assisted process used to produce an oxide ceramic on metal surface ${ }^{1}$. In this process, high voltages (400-700 V) are used between two electrodes. High voltages cause the dielectric breakdown of the double layer due to excessive production of electrons and ions. These particles are accelerated towards the anode producing an avalanche of electrons that lead to the formation of several micro-discharges on the electrode/electrolyte interface. These micro-discharges produce heating-cooling cycles that determine the thermal and chemical conditions on such interface, having a significant impact on chemical composition, phase evolution and morphology of the coatings ${ }^{2,3}$.

The literature has reported some hypothetical models of micro-discharges formation which are based on the dieletric rupture of the oxide film, due to the appearance of strong electrical fields in preferential areas (defects and micropores $)^{4}$. Recent studies ${ }^{5-12}$ have utilized the optical emission spectroscopy technique (OES) to investigate the complex phenomena involved in this process. By diagnosing the plasma through OES, Hussein et al. ${ }^{6}$ have proposed the existence of three discharge types (A, B and C), to explain the interaction mechanism of the plasma in the PEO process on pure aluminum substrate. The strong B-type discharge occurs at the metal/oxide interface through "localized melt channels". The A and C type discharges occurs at the

*e-mail: clodomiro.jr@hotmail.com oxide/electrolyte interface, through the pores. The frequency with which they happen can vary according to the electric parameters of the process, such as: current density, treatment time, current mode, frequency and duty cycle ${ }^{5,13-16}$.

There is a considerable numbers of works that shows that pulsed source mode helps to control the duration and intensity of the micro-discharges and to improve the coating characteristics through parameter settings such as pulse on $\left(\mathrm{T}_{\text {on }}\right)$ and off time $\left(\mathrm{T}_{\text {off }}\right)$, duty cycle and frequency $y^{5,9,11,17}$. The $\mathrm{T}_{\text {on }}$ pulse supplies the time for the melting of the aluminum and sintering of the oxide layer, while on the $T_{\text {off }}$ pulse the micro-discharges are interrupted, allowing the surface of the oxide to $\operatorname{cool}^{17,18}$. Up to now, plasma electrolytic oxidation (PEO) has been produced in ultra-low frequency $(<1 \mathrm{kHz})$ pulsed voltage using high concentration alkaline-silicate electrolytic $\left(\mathrm{Na}_{2} \mathrm{SiO}_{3}>8 \text { g. } \mathrm{L}^{-1} \text { with presence of } \mathrm{KOH}\right)^{9,15,16,18}$. According to Pillai et al. ${ }^{15}$, when low electrolytic concentration is used, high pulse frequency must to be applied to decrease the breakdown voltage and the final output voltage. Besides that, helps to minimize the voltage fluctuation. However, Hussein et al. ${ }^{17}$ reported that using frequencies above $20 \mathrm{kHz}$ results in the formation of oxide layers with low homogeneity, high porosity and low adhesion which may not benefit the PEO coatings. Besides that, studying the phase distribution of the PEO treatment on aluminum 6061 alloys with pulsed current, Dehnavi et al. ${ }^{13}$ found that an increase of the $\mathrm{T}_{\text {on }}$ pulse in low frequencies caused an increase of the $\gamma \rightarrow \alpha-\mathrm{Al}_{2} \mathrm{O}_{3}$ phase transformation, while a low $\mathrm{T}_{\text {on }}$ could result in more porous and thicker coatings. 
Based on this knowledge, plasma electrolytic oxidation (PEO) was performed using shorter square current pulses (frequency $>1 \mathrm{KHz}$ ) than traditionally used so far. Short pulses modify both the electric double layer and the diffusion layer. It was investigated, in situ, with the aid of optical emission spectroscopy (OES) and CCD camera, the species of plasma and respective configurations of the electric discharges formed during the process. The OES technique will help to understand the color changes in the micro-discharges and the distribution and formation of phases present in the coating throughout the process. Besides that, the influence of the pulse's width and treatment time over the formation of the coatings was investigated.

\section{Experimental Procedures}

\subsection{Sample preparation}

Disc-shaped aluminum Al-1050 (99,5\% Al) samples, measuring $20 \mathrm{~mm} \times 4 \mathrm{~mm}$ (diameter $\times$ thickness), were electrically coupled to a copper wire and embedded in resin, in such a way that only one surface was exposed to the treatment. Before treatment, the samples were sanded and polished with alumina. The polished substrates were washed in an ultrasonic bath using detergent for $300 \mathrm{~s}$ for degreasing and cleaning.

\subsection{PEO Treatment}

The PEO treatment was carried out at an electrolytic cell composed by an acrylic container with $400 \mathrm{ml}$ of an electrolytic solution of 2 g.L $\mathrm{L}^{-1} \mathrm{Na}_{2} \mathrm{SiO}_{3}, \mathrm{pH}$ de 11.5. An Al-1050 sample, dimensions $20 \mathrm{~mm} \times 4 \mathrm{~mm}$ (diameter $\times$ thickness), was used as anode, while a stainless steel plate, dimensions $50 \mathrm{~mm} \times 50 \mathrm{~mm}$ (length $\times$ height), was used as a cathode (Figure 1). A unipolar pulsed current with square waveform was applied. Current pulses $\mathrm{T}_{\text {on }}$ was set to $50 \mu \mathrm{s}$, $100 \mu \mathrm{s}$ or $150 \mu \mathrm{s}$, while the $\mathrm{T}_{\text {off }}$ pulse repetition time was set to $150 \mu \mathrm{s}$. The durations of the treatment were 2 or 12 minutes; current density was set to $27 \mathrm{~A} . \mathrm{dm}^{-2}$, temperature to $25^{\circ} \mathrm{C}$ and stirring to $30 \mathrm{rpm}$, to avoid loss of conductivity in the medium. To capture the radiation emitted by plasma, a silica optic fiber, measuring $0.6 \mathrm{~mm}$ of diameter, was inserted into the cell $5 \mathrm{~mm}$ away from the sample. The fiber was coupled to an optic emission spectrometer with optic resolution ranging from 0.1 to $10 \mathrm{~nm}$, USB 4000, ocean optics and a Toshiba TCD1304AP detector, with optic response ranging from 200-1100 nm. Atomic lines were identified using the NIST Atomic Spectra Database Lines Data and Handbook of Basic Atomic Spectroscopic Data ${ }^{19}$. Real-time images of the plasma were also captured through a Digital video camera (16 Mpx, $4608 \times 3456$ pixel, $30 \mathrm{fps})$, placed to $15 \mathrm{~cm}$ away from the sample.

\subsection{Characterization}

Micrographs of the surface and thickness of the coating were obtained through a Tescan Vega3 high-resolution scanning electron microscope (SEM). Chemical analyses of the surface of the samples were conducted through a dispersive energy $\mathrm{x}$-ray spectrometer coupled to the SEM. The pore size, number and distribution were analyzed by using the ImageJ software. The crystallographic phases were analyzed through the X-ray diffraction technique, by using a Shimadzu ${ }^{\circledR}$ XRD-6000 X-ray diffractometer with $\mathrm{Cu} \mathrm{K} \alpha$ radiation ( $0.154 \mathrm{~nm}$ wavelength). To analyze the layer in different depths, the GIXRD technique was used, by coupling a thin-layer analysis accessory (THA-1101) to the diffractometer.

\section{Results and Discussion}

\subsection{Voltage response and OES analysis}

The operating voltage-time response for the three current pulse used are shown in Figure 2a. On stage I of the treatment, a sharp increase in voltage can be observed, due to the conventional electrolysis process, with a dielectric oxide film forming on the surface of the substrate ${ }^{20}$. It was observed that the beginning of the curvature on the graphic is the moment in which the dielectric breakdown of the film is reached, and stage II begins. In this stage, the first micro-discharges

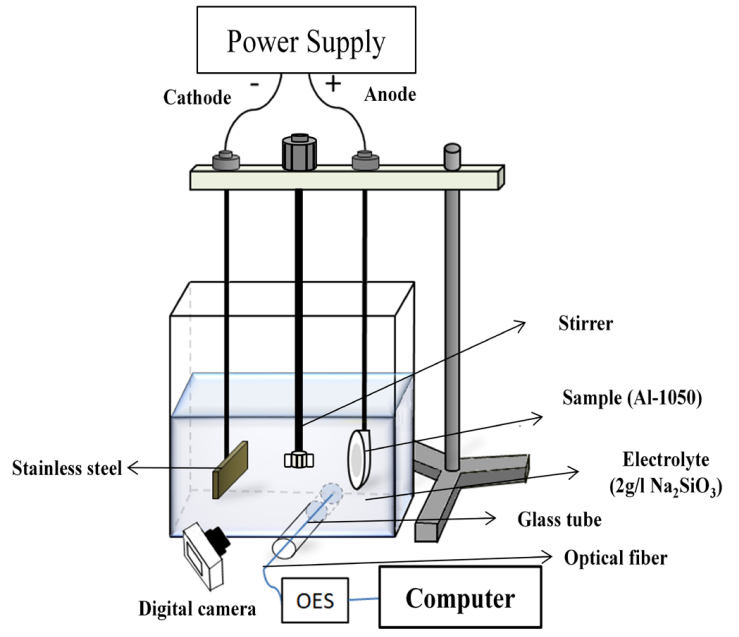

Figure 1. Schematic diagram of the experimental apparatus.

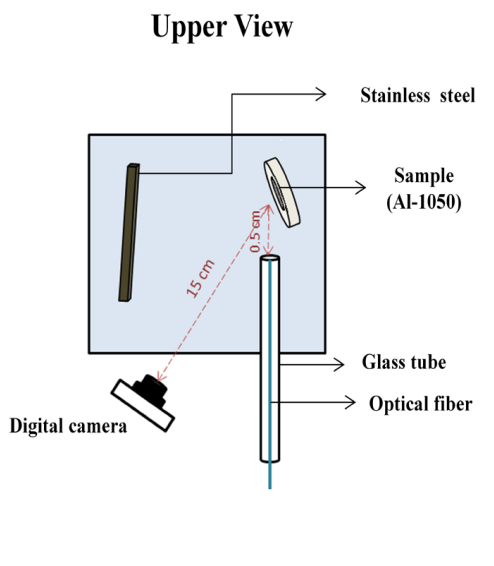


are observed, and the voltage starts to rises slowly ${ }^{9}$. On the treatments with $\mathrm{T}_{\text {on }}=100$ and $150 \mu \mathrm{s}$, the dielectric breakdown is reached in a shorter time (approximately $13 \mathrm{~s}$ and $11 \mathrm{~s}$, respectively), while for $\mathrm{T}_{\text {on }}=50 \mu \mathrm{s}$ the dielectric rupture happens at $23 \mathrm{~s}$, approximately, probably due to the low growth rate of the film in this condition. After the second stage is reached, it is possible to visualize another change in the slop of the voltage-time curves which is associated with the transition to the stage III. Observing the species of the plasma during this transition moment (Figure 2b), it can be seen variations of the relative intensities of the present species.

It is possible to observe that the plasma is mainly composed of Al I $(396,15 \mathrm{~nm})$ from the substrate, and $\mathrm{OH}(287,86 \mathrm{~nm})$, O II $(313,47 \mathrm{~nm})$, O I $(777,19 \mathrm{~nm}) \mathrm{Na}$ I $(589,50 \mathrm{~nm})$, Si I $(288,16 \mathrm{~nm})$ and $\mathrm{H}_{\alpha}(656,28 \mathrm{~nm})$, from the electrolyte.

The appearance of atomic aluminum peaks (Al I) is a consequence of the discharges that are able to penetrate the thin oxide layer and reach the substrate, causing the melting

(a)

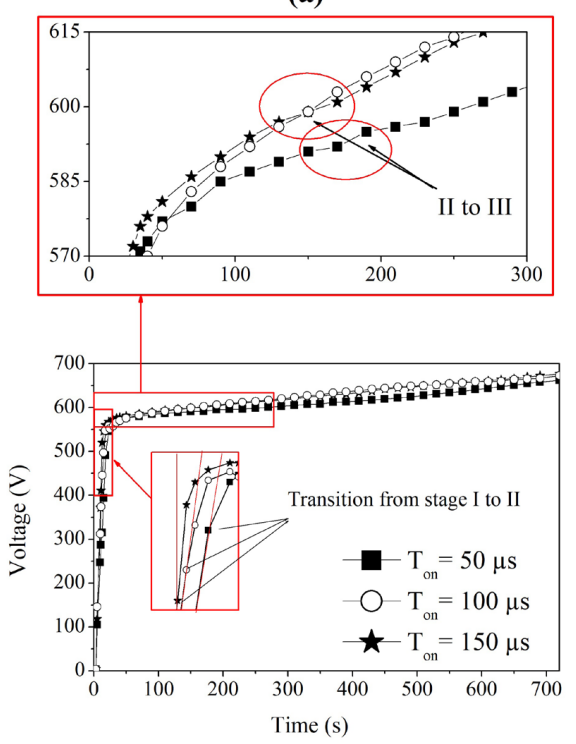

and ejection of the aluminum to the surface $e^{6,21}$. As the layer grows, it becomes harder for the discharges to pass through, and, consequentially less aluminum is ejected and the intensity of the Al I peaks $\left(\mathrm{I}_{\mathrm{Al}}\right)$ starts to reduce. When it reaches stage III, the sample has a surface with higher pore density, but it also needs a higher potential to break the dielectric barrier of the oxide layer that is produced. Only sites with high charge concentration are liable to extract aluminum through micro-arcs. This phenomenon can be illustrated by the documented visual aspect for the three studied conditions (Figure 3).

Pictures of the visual aspect of micro-discharges during the first moments of the process shows that in the discharges with $\mathrm{T}_{\text {on }}=100 \mu \mathrm{s}$ and $150 \mu$ s there is a higher optic density on the edge of the sample and then spreads through the entire surface, leaving the micro-arcs more spaced. Samples treated with the $50 \mu$ s pulse display more uniform micro-discharges throughout the process. This is possibly due to the edge effect (tendency of charge accumulation on edges or holes) being

(b)

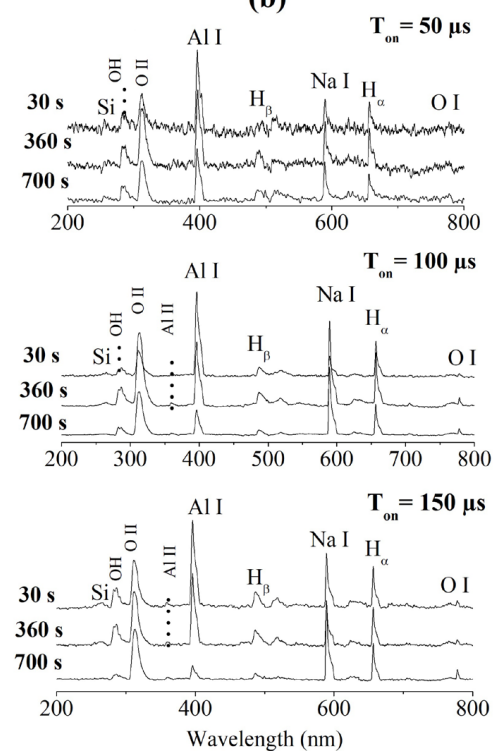

Figure 2. (a) Operating voltage and time response for the three $T_{\text {on }}$ current pulse used on PEO process; (b) Variation of the optical emission spectrum for the three $\mathrm{T}_{\text {on }}$ current pulse.
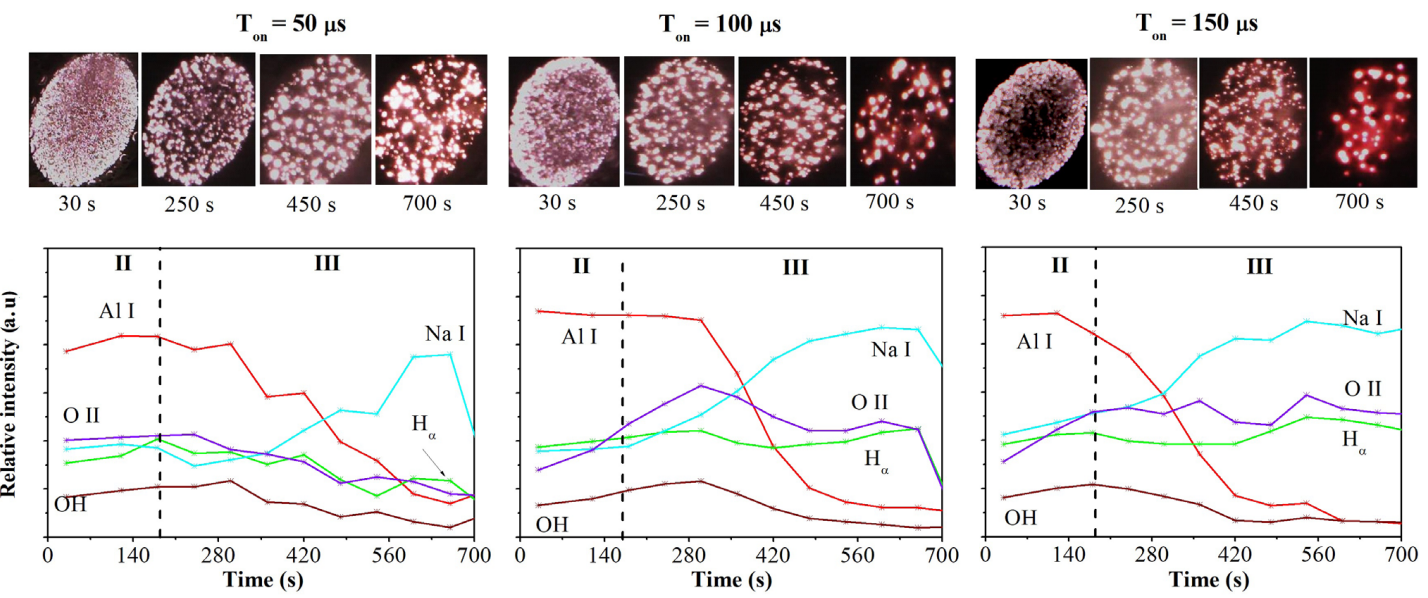

Figure 3. Evolution of the micro-discharges and intensity of the peaks of the chemical species with PEO treatment time on stages II and III. 
higher for wider pulses. Besides the edge, other sites such as oxide particles and pores are charge concentrators ${ }^{9,22,23}$, exerting more influence when the pulse is wider.

The change of color of the micro-arcs is more perceptible when the pulse is wider. The white color is related to the presence of all visible wavelengths related to the different species present. The orange coloring might be due to the presence of sodium and hydrogen in the solution, which have their intensities increased during this stage.

It was also possible to visualize a temporal increase of the atomic sodium $(\mathrm{Na} \mathrm{I})$ peak intensities. EDS analysis showed only the presence of Al, O and $\mathrm{Si}$ (Figure 4) in the samples. The presence of sodium could not be verified, even though it was present in the plasma. This seeming inconsistence was solved when small white particles that were supernatant

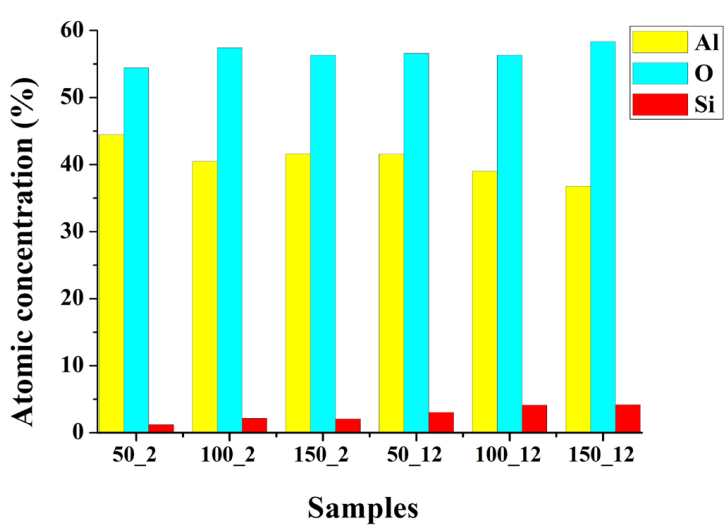

Figure 4. EDS analysis of the samples surface after plasma electrolytic oxidation. on the electrolytes for the 12 min processes were analyzed through SEM/EDS. It was verified that these particles, with average diameter of $50 \mu \mathrm{m}$, were composed predominantly of oxygen (80 at.\%) and $\mathrm{Na}(12$ at.\%), as well as smaller quantities of $\mathrm{Al}$ and $\mathrm{Si}$ (4 and 2 at.\%, respectively).

It is also possible to observe in Figure 4 that aluminum on the surface follows the same trend observed in the plasma, that is, the concentration diminishes as the process goes on. The inverse happens to the $\mathrm{Si}$ concentration

\subsection{Morphology}

Figure 5 shows the superficial micrographs of the coatings obtained through PEO using different pulses during 2 and 12 minutes of treatment. With 2 minutes of treatment (Figure 5a, 5b and 5c), the surface morphology in the three conditions is very similar with typical "porous coralline" structure. The coatings presented great quantities of pores and small nodular regions that, according to Hussein et al. ${ }^{6}$ come from weak discharges that happen in the pores or in micro-cracks filled with electrolyte (Type $\mathrm{A}$ and $\mathrm{C}$ discharges). The influence of the pulse width on the surface morphology becomes more visible with 12 minutes of treatment (Figure 5d, 5e and 5f). It is possible to observe that surfaces are covered by "pancake" type structures, with a few open and closed pores at the center of the pancake. These pancake structures are consequence of the strong micro-discharges that occur in the localized melt channels (type B discharges). Such discharges are responsible for the ejection of large masses of molten oxide to the surface, that rapidly solidified when in contact with the electrolyte, creating structures resembling pancakes ${ }^{6}$. It is also possible to observe small nodular structures coming
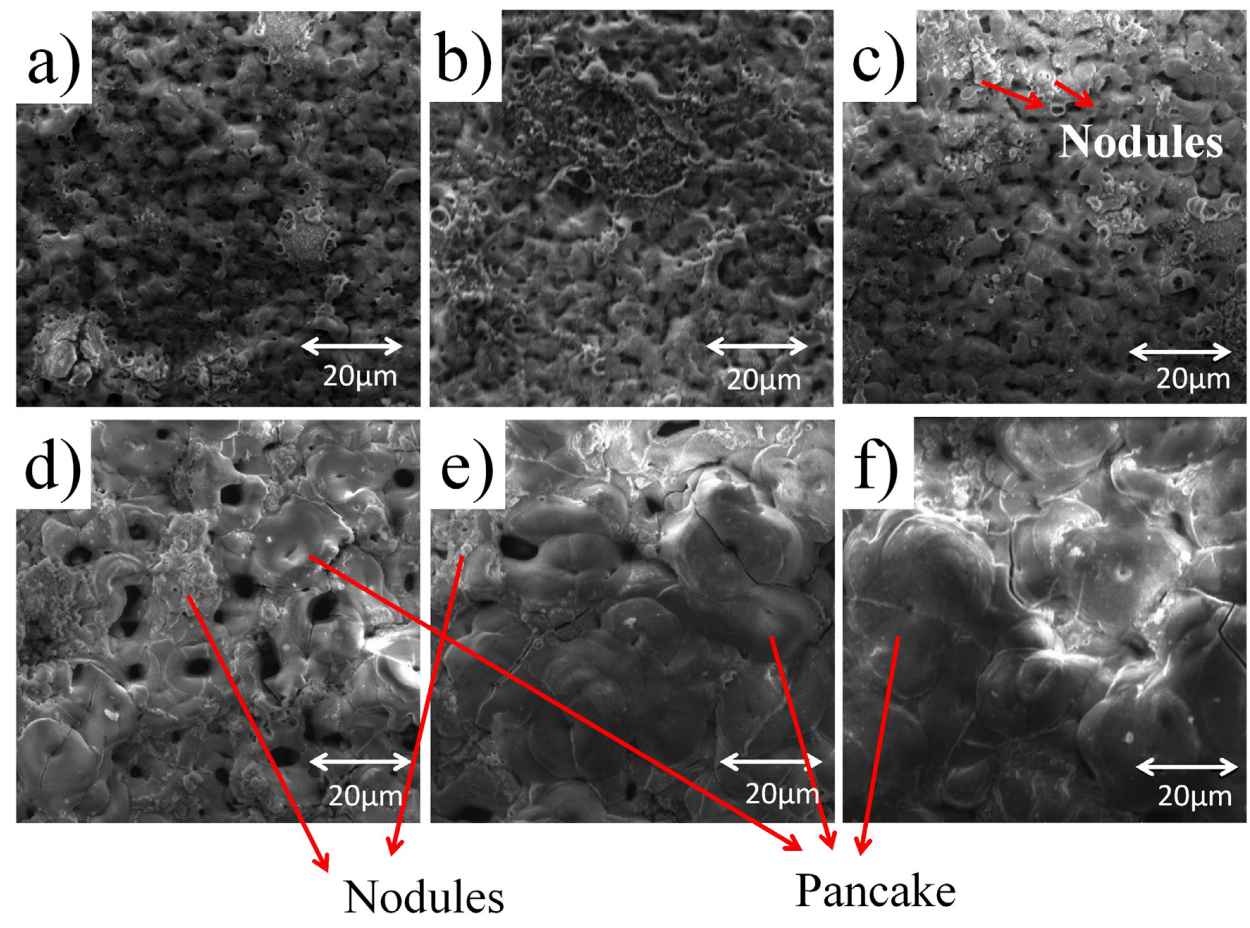

Figure 5. Surface morphology of the PEO treated samples. (a) 50_2; (b) 100_2 ; (c) 150_2; (d) 50_12 (e) 100_12; (f) 150_12. 
out of the micro-cracks. For shorter pulse width, the pores are well distributed because of the uniform distribution of the micro-arcs.

The porosity of the coating is heavily influenced by the pulse changes, mainly when the treatment time is longer. Figure 6 shows the topographical characteristics of the coatings.

When the time is kept constant, it is possible to observe that an increase of $\mathrm{T}_{\text {on }}$ provides a reduction of the superficial porosity, but it does not have a great influence over the average pore size. With 12 minutes of treatment, these effects are more visible. An increase of $\mathrm{T}_{\text {on }}$ causes an increase of plasma temperature, and thus the quantity of material that is ejected through the localized melt channels is high enough to fill the entire channel. Because of this, the wide pores at the center of the pancakes are more predominant on the samples obtained at $\mathrm{T}_{\text {on }}=50 \mu \mathrm{s}$ (Figure $5 \mathrm{~d}$ ) than at $\mathrm{T}_{\text {on }}=100 \mu \mathrm{s}$ and $\mathrm{T}_{\text {on }}=150 \mu \mathrm{s}$ (Figure 5e and 5f).

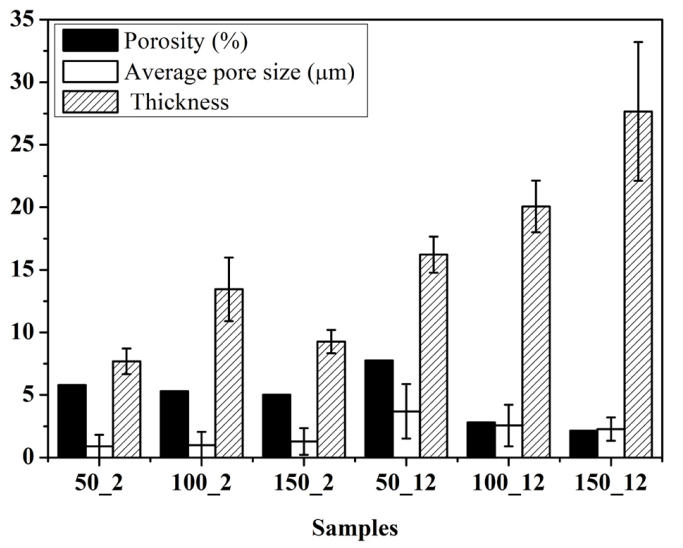

Figure 6. Topographical characteristics of the surface of the PEO coatings: porosity, average pore size and thickness.
An increase in coating thickness with pulse width and treatment time is also observed. The micrographs of the cross-sections of the coatings prepared under different conditions are shown in Figure 7 . With the increase in treatment time and pulse current, metallurgical processes become more frequent (as micro-discharges become more populous and intense) than electrochemical processes at the substrate/coating interface. Thus, the melting and solidification of the coating at this interface favors adherence to the substrate. It is also possible to observe the presence of small pores mainly in the samples treated with small $\mathrm{T}_{\text {on. }}$ The same behavior was observed by Dehnavi et al. ${ }^{24}$ working with low frequency pulse current. The presence of pores may be due to the trapping of oxygen or other types of gases during the short discharges ${ }^{25}$.

\subsection{Phase Identification}

In the $x$-ray diffractograms obtained by using the Bragg-Brentano geometry (Figure $8 \mathrm{a}$ ), very intense peaks can be verified, referring to the Al phase (ICDD card 00-004-0787) and to the impurities present in the substrates, followed by other less intense peaks identified as the $\gamma-\mathrm{Al}_{2} \mathrm{O}_{3}$ (ICDD card 00-002-1420), $\alpha-\mathrm{Al}_{2} \mathrm{O}_{3}$ (ICDD card 00-046-1212) shown in the magnification regions in Figure 8b.

For the grazing incidence of $1^{\circ}$, which gives us information about the most superficial region (Figure 9), is observed that the predominant phase on the surface is $\gamma-\mathrm{Al}_{2} \mathrm{O}_{3}$ with low intensity peaks of $\mathrm{SiO}_{2}$ phase (COD card 96-900-1581). No $\alpha$ phase peaks are observed. As the presence of the $\alpha$ phase is only observed in the bragg-brettano diffratrogram (Figure 8b), it can be concluded that this phase is concentrated in the inner layer of the coating. This result allows us to assume that the $\alpha$ phase is present internally only in the samples treated with high $t_{\text {on }}$ and treatment time. This is because the

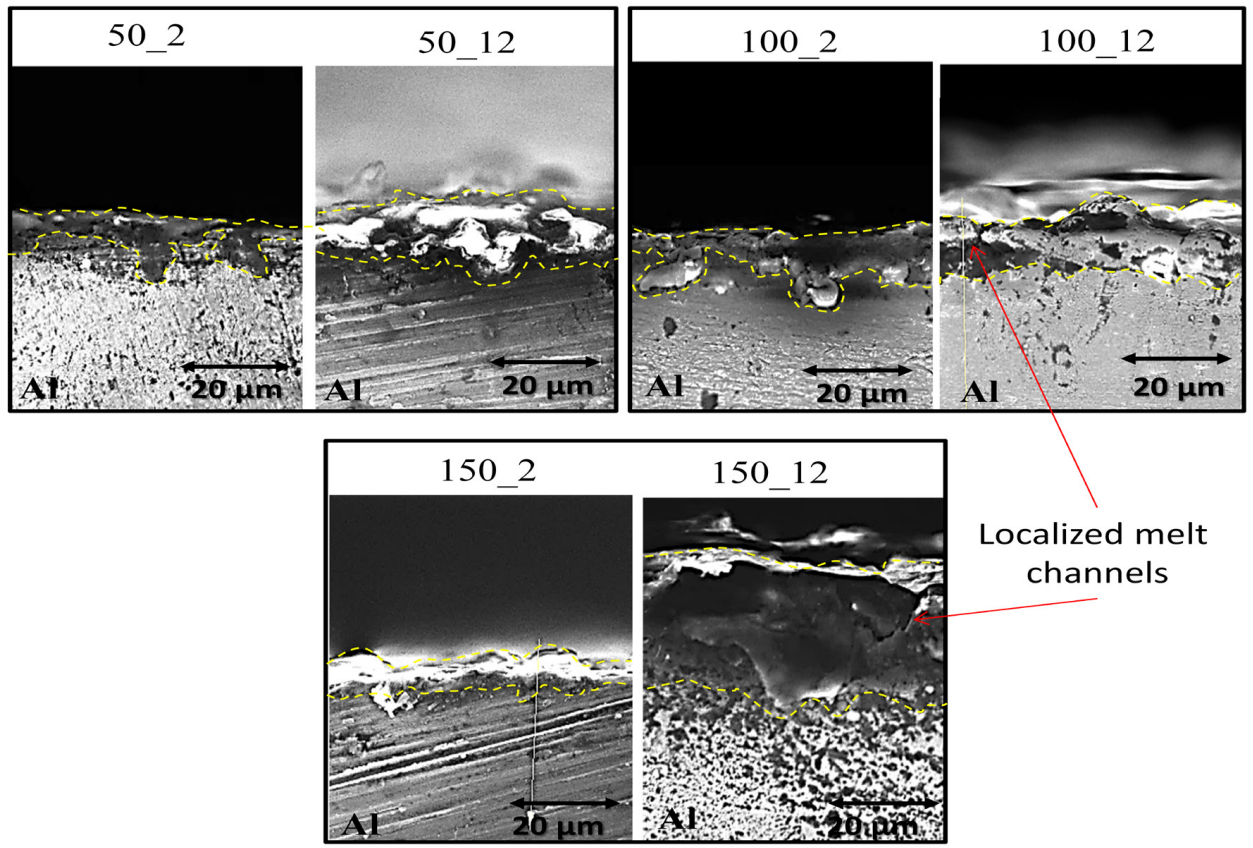

Figure 7. SEM micrographs of the cross-sections of the PEO coatings prepared under different conditions. 


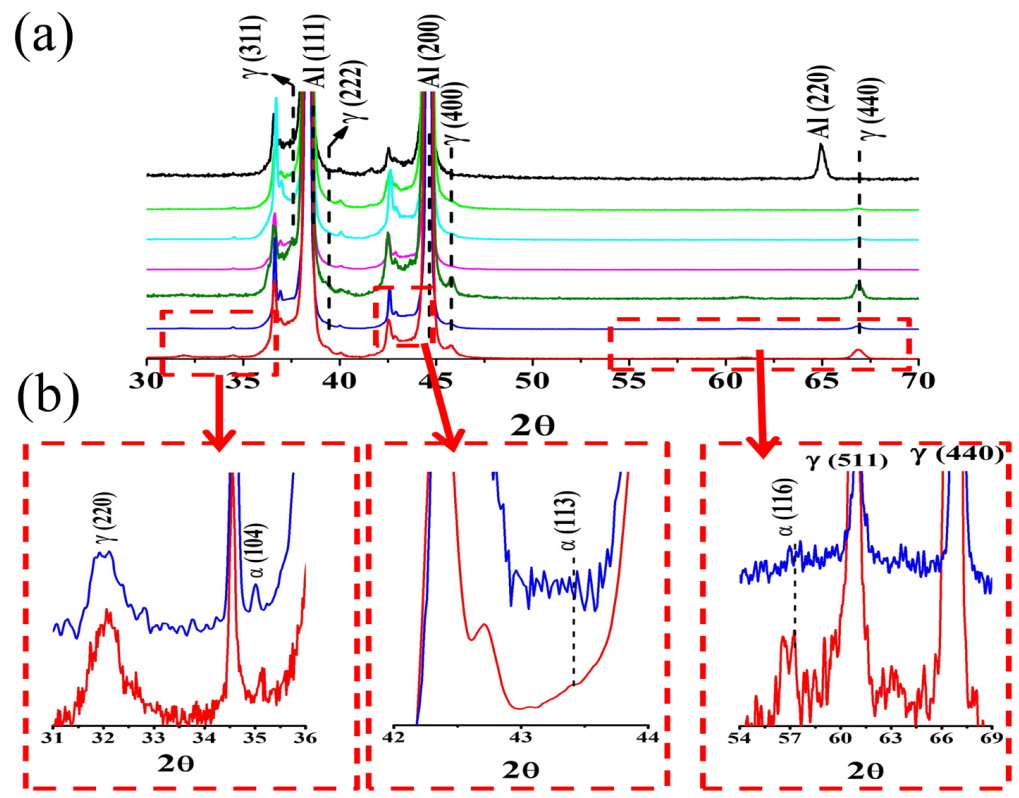

Figure 8. (a) XRD pattern of PEO treated samples using Bragg-Brentano geometry; (b) Details for less intense peaks of samples 100_12 and 150_12.

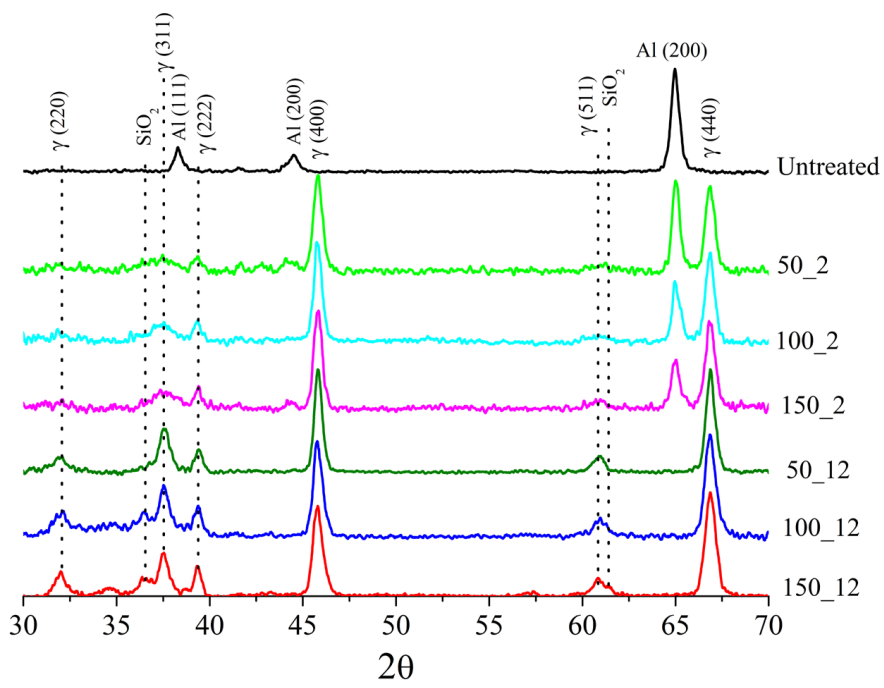

Figure 9. XRD pattern of the PEO samples using grazing incidence of $1^{\circ}$.

discharges have enough energy to transform the initially formed phase $\gamma$ into phase $\alpha$, formed by heating the phase $\gamma$ between $800^{\circ}$ and $1200^{\circ} \mathrm{C}$. The high energy of these discharges allows penetrating the coating, generating melt channels through which molten aluminum is ejected. The part that touches the solution is quickly cooled, favoring the formation of the $\gamma-\mathrm{Al}_{2} \mathrm{O}_{3}$ phase. However, the ceramic mass that is located under the surface stays warm, transforming into $\alpha-\mathrm{Al}_{2} \mathrm{O}_{3}$.

In the samples treated with small pulse, as the thickness is small, heat does not accumulate along the coating. This, coupled with the high cooling rate, makes it difficult to transform from phase $\gamma$ to phase $\alpha$.

The presence of $\mathrm{SiO}_{2}$ is also supported by the EDS analyses of the oxidized surfaces (Figure 4), where it is possible to verify that the atomic concentrations of $\mathrm{Si}$ increased with pulse width and treatment time. Mapping done through energy dispersive spectroscopy (EDS) (Figure 10) shows the distribution of $\mathrm{O}, \mathrm{Al}$ and $\mathrm{Si}$ on the surface of the samples. It can be verified that the Si does not present a homogeneous distribution, being located preferentially on the borders of the pores or in proximity to cracks, where the localized melt channels are found.

Since these regions are the ones that present higher temperatures, we can suppose that the $\mathrm{SiO}_{2}$ formation has happened due the combination of $\mathrm{Si}$ and $\mathrm{O}$ atoms originated from the dissociation of $\mathrm{SiO}_{3}{ }^{-2}$ in the plasma core. This hypothesis is supported by the OES spectrum in Figure $2 \mathrm{~b}$ showing peaks of $\mathrm{Si}(288.16 \mathrm{~nm})$ and O I (777.19 nm). 

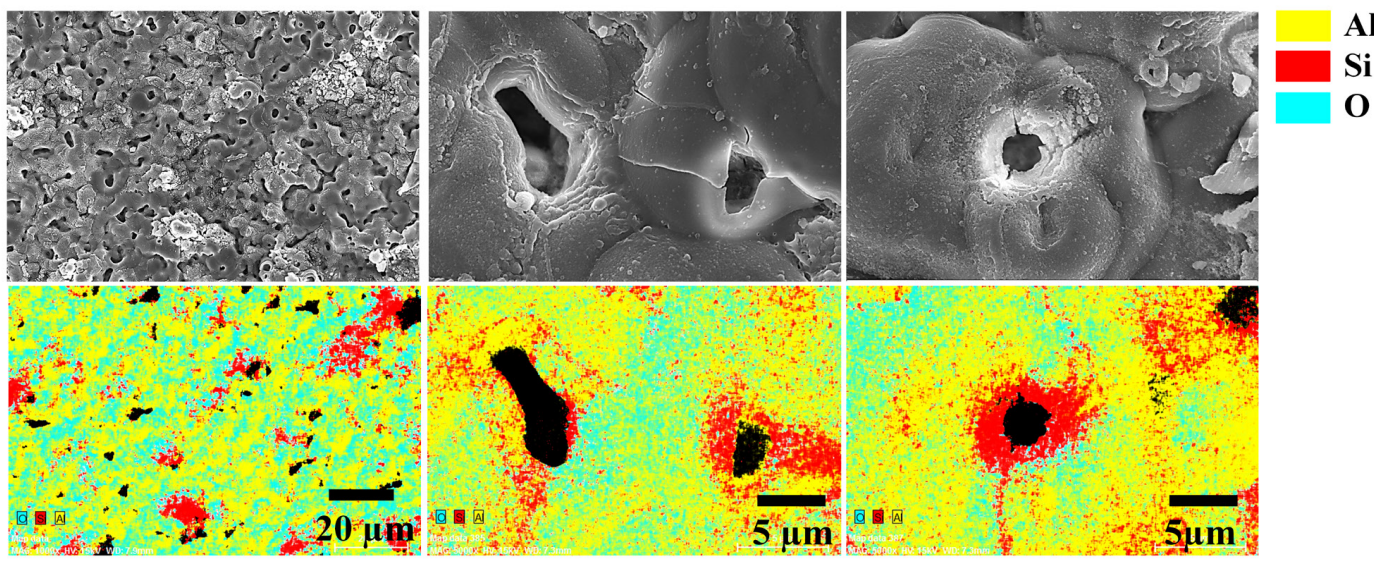

Figure 10. EDS mapping images showing distribution of $\mathrm{Al}, \mathrm{O}$ and $\mathrm{Si}$, where $\mathrm{Si}$ is preferentially located at the edges of the pores.

\section{Conclusion}

Six different condition of PEO treatment were carried out in diluted sodium silicate electrolytes at high frequency current pulse to produce oxide coating on a pure $\mathrm{Al}$ substrate.

For small $\mathrm{T}_{\text {on }}$, sparks was less intense but homogeneously distributed, controlling the strong discharging. The presence of sodium in the plasma was verified for longer time, but it only participates of electrolyte reaction. Particles containing predominantly oxygen and sodium were observed as supernatants in the electrolyte.

Porosity and average pore size increase when the pulse decreases. All the samples obtained presented good bonding between the coating and the substrate. It was found that concentration of $\mathrm{O}$ and $\mathrm{Si}$ on the samples surface increases with the treatment time and pulse width. The opposite happens for Al.

Regarding the evolution of the ceramic coating, the presence of phase $\alpha-\mathrm{Al}_{2} \mathrm{O}_{3}$ predominantly in the internal layer and $\gamma-\mathrm{Al}_{2} \mathrm{O}_{3}$ phase on the surface was verified for longer $\mathrm{T}_{\text {on }}$. This result suggests that the $\gamma-\mathrm{Al}_{2} \mathrm{O}_{3}$ phase is precursor during the process, changing to $\alpha-\mathrm{Al}_{2} \mathrm{O}_{3}$ phase due local heating. Although we used a diluted silicate electrolytic it was verify the presence of $\mathrm{SiO}_{2}$ phase on the borders of the pores or in proximity to cracks, especially in the treatments with higher pulse width.

\section{Acknowledgement}

The authors are grateful to the Brazilian Agencies CAPES and $\mathrm{CNPq}$ for financial support.

\section{References}

1. Yerokhin AL, Nie X, Leyland A, Matthews A, Dowey SJ. Plasma electrolysis for surface engineering. Surf Coat Tech. 1999;122(23):73-93. http://dx.doi.org/10.1016/S0257-8972(99)00441-7.

2. Zhang Y, Wu Y, Chen D, Wang R, Li D, Guo C, et al. Microstructures and growth mechanisms of plasma electrolytic oxidation coatings on aluminium at different current densities. Surf Coat Tech. 2017;321:236-46. http://dx.doi.org/10.1016/j. surfcoat.2017.04.064.

3. Khan RHU, Yerokhin A, Li X, Dong H, Matthews A. Surface characterisation of DC plasma electrolytic oxidation treated 6082 aluminium alloy: effect of current density and electrolyte concentration. Surf Coat Tech. 2010;205(6):1679-88. http:// dx.doi.org/10.1016/j.surfcoat.2010.04.052.

4. Yerokhin AL, Snizhko LO, Gurevina NL, Leyland A, Pilkington A, Matthews A. Discharge characterization in plasma electrolytic oxidation of aluminium. J Phys D Appl Phys. 2003;36(17):211020. http://dx.doi.org/10.1088/0022-3727/36/17/314.

5. Dunleavy CS, Golosnoy IO, Curran JA, Clyne TW. Characterisation of discharge events during plasma electrolytic oxidation. Surf Coat Tech. 2009;203(22):3410-9. http://dx.doi.org/10.1016/j. surfcoat.2009.05.004.

6. Hussein RO, Nie X, Northwood DO, Yerokhin A, Matthews A. Spectroscopic study of electrolytic plasma and discharging behaviour during the plasma electrolytic oxidation (PEO) process. J Phys D Appl Phys. 2010;43(10):105203. http:// dx.doi.org/10.1088/0022-3727/43/10/105203.

7. Jovović J, Stojadinović S, Šišović NM, Konjević N. Spectroscopic study of plasma during electrolytic oxidation of magnesium- and aluminium-alloy. J Quant Spectrosc Radiat Transf. 2012;113(15):1928-37. http://dx.doi.org/10.1016/j. jqsrt.2012.06.008.

8. Wang L, Chen L, Yan Z, Fu W. Optical emission spectroscopy studies of discharge mechanism and plasma characteristics during plasma electrolytic oxidation of magnesium in different electrolytes. Surf Coat Tech. 2010;205(6):1651-8. http://dx.doi. org/10.1016/j.surfcoat.2010.10.022.

9. Dehnavi V, Luan BL, Shoesmith DW, Liu XY, Rohani S. Effect of duty cycle and applied current frequency on plasma electrolytic oxidation (PEO) coating growth behavior. Surf Coat Tech. 2013;226:100-7. http://dx.doi.org/10.1016/j. surfcoat.2013.03.041.

10. Cheng Y, Wang T, Li S, Cheng Y, Cao J, Xie H. The effects of anion deposition and negative pulse on the behaviours of plasma electrolytic oxidation (PEO): a systematic study of the PEO of a Zirlo alloy in aluminate electrolytes. Electrochim Acta. 2017;225:47-68. http://dx.doi.org/10.1016/j. electacta.2016.12.115.

11. Hussein RO, Nie X, Northwood DO. Influence of process parameters on electrolytic plasma discharging behaviour and aluminum oxide coating microstructure. Surf Coat Tech. 2010;205(6):1659-67. http://dx.doi.org/10.1016/j.surfcoat.2010.08.059.

12. Yang X, Chen L, Qu Y, Liu R, Wei K, Xue W. Optical emission spectroscopy of plasma electrolytic oxidation process on 7075 aluminum alloy. Surf Coat Tech. 2017;324:18-25. http://dx.doi. org/10.1016/j.surfcoat.2017.05.005.

13. Dehnavi V, Liu XY, Luan BL, Shoesmith DW, Rohani S. Phase transformation in plasma electrolytic oxidation coatings on 6061 aluminum alloy. Surf Coat Tech. 2014;251:106-14. http:// dx.doi.org/10.1016/j.surfcoat.2014.04.010. 
14. Lu X, Mohedano M, Blawert C, Matykina E, Arrabal R, Kainer $\mathrm{KU}$, et al. Plasma electrolytic oxidation coatings with particle additions: a review. Surf Coat Tech. 2016;307:1165-82. http:// dx.doi.org/10.1016/j.surfcoat.2016.08.055.

15. Pillai AM, Rajendra A, Sharma AK. Influence of process parameters on growth behaviour and properties of coatings obtained by plasma electrolytic oxidation (PEO) on AA. J Appl Electrochem. 2018;48(5):543-57. http://dx.doi.org/10.1007/ s10800-018-1186-2.

16. Martin J, Melhem A, Shchedrina I, Duchanoy T, Nominé A, Henrion $\mathrm{G}$, et al. Effects of electrical parameters on plasma electrolytic oxidation of aluminium. Surf Coat Tech. 2013;221:706. http://dx.doi.org/10.1016/j.surfcoat.2013.01.029.

17. Hussein RO, Northwood DO, Nie X. Coating growth behavior during the plasma electrolytic oxidation process. J Vac Sci Technol A. 2010;28(4):766-73. http://dx.doi.org/10.1116/1.3429583.

18. Al Bosta MMS, Ma K-J, Chien H-H. The effect of MAO processing time on surface properties and low temperature infrared emissivity of ceramic coating on aluminium 6061 alloy. Infrared Phys Technol Technol. 2013;60:323-34. http:// dx.doi.org/10.1016/j.infrared.2013.06.006.

19. Sansonetti JE, Martin WC. Handbook of basic atomic spectroscopic data. J Phys Chem Ref Data. 2005;34(4):1559-2259. http:// dx.doi.org/10.1063/1.1800011.
20. Guan Y, Xia Y, Li G. Growth mechanism and corrosion behavior of ceramic coatings on aluminum produced by autocontrol AC pulse PEO. Surf Coat Tech. 2008;202(19):4602-12. http:// dx.doi.org/10.1016/j.surfcoat.2008.03.031.

21. Stojadinovic S, Vasilic R, Belca I, Petkovic M, Kasalica B, Nedic $\mathrm{Z}$, et al. Characterization of the plasma electrolytic oxidation of aluminium in sodium tungstate. Corros Sci. 2010;52(10):325865. http://dx.doi.org/10.1016/j.corsci.2010.05.042.

22. Liu R, Wu J, Xue W, Qu Y, Yang C, Wang B, et al. Discharge behaviors during plasma electrolytic oxidation on aluminum alloy. Mater Chem Phys. 2014;148(1-2):284-92. http://dx.doi. org/10.1016/j.matchemphys.2014.07.045.

23. Klapkiv MD, Nykyforchyn HMM, Posuvailo VM. Spectral analysis of an electrolytic plasma in the process of synthesis of aluminum oxide. Mater Sci. 1995;30(3):333-43. http://dx.doi. org/10.1007/BF00569685.

24. Dehnavi V, Luan BL, Liu XY, Shoesmith DW, Rohani S. Correlation between plasma electrolytic oxidation treatment stages and coating microstructure on aluminum under unipolar pulsed DC mode. Surf Coat Tech. 2015;269(1):91-9. http:// dx.doi.org/10.1016/j.surfcoat.2014.11.007.

25. Curran JA, Clyne TW. Porosity in plasma electrolytic oxide coatings. Acta Mater. 2006;54(7):1985-93. http://dx.doi. org/10.1016/j.actamat.2005.12.029. 